\title{
ALTERAÇÕES FÍSICAS E QUÍMICAS DO SOLO EM VIRTUDE DE CONSTRUÇÕES TERMÍTICAS NO NORTE DE TOCANTINS
}

\author{
Leonardo Bernardes Taverny de Oliveira ${ }^{1}$, Antonio Clementino dos Santos ${ }^{2}$, Sabino Pereira da Silva Neto ${ }^{3}$, \\ José Expedito Cavalcante da Silva ${ }^{4}$, Joseilson Alves de Paiva ${ }^{4}$
}

\begin{abstract}
RESUMO
A ação dos térmitas na pastagem promove mudanças químicas e físicas que auxiliam no incremento qualitativo no solo, como aeração, aumento do teor de argila na superfície do solo e de nutrientes elaborados. Nesse sentido objetivou-se verificar as alterações ocorridas em solos sob pastagem e em termiteiros em função da atuação dos térmitas no norte do Tocantins. O diagnóstico foi realizado em Neossolo Quartzarênico órtico e Latossolo Vermelho distrófico comparando os teores de argila, silte, areia, pH, matéria orgânica, fósforo, potássio, cálcio, magnésio e alumínio do solo adjacente aos termiteiros e as partes fracionadas dos mesmos (topo, meio e base). Não foram encontradas diferenças nos valores de $\mathrm{P}, \mathrm{MO}$, areia e silte entre as duas classes de solos. No entanto, quando se comparou topos entre centros, bases e área adjacente, os resultados foram distintos. Os cupins são componentes essenciais dos solos por serem de grande importância na ciclagem de nutrientes e atuarem de forma direta na pedogênese do solo, melhorando os teores de argila e silte antes percolados, além de influenciar na translocação e disponibilidade de alguns macronutrientes primários e secundários essenciais as plantas, e aumentar a porosidade, aeração, infiltração de água de solos.
\end{abstract}

Palavras-chave: pastagem, termiteiro, solo.

\section{ABSTRACT}

\section{PHYSICAL AND CHEMICAL CHANGES IN SOIL UNDER TERMITE HILLS IN TOCANTINS}

The action of termites in pasture land leads to chemical and physical changes that help improve soil quality, such as aeration, increased clay content in surface soil and nutrient recycling. This study was done to verify the changes in pasture soil and termite hills in northern Tocantins. The study was done in a sandy and oxisol soil by comparing clay, silt, sand, $\mathrm{pH}$, organic matter, phosphorus, potassium, calcium, magnesium and aluminum in soil adjacent to the termite hills and in the top, middle and base portion of the hills. There was no difference in the values of P, OM, sand and silt between the two classes of soils. However, when tops were compared to center, base and the adjacent area, the results was different. Termites were an essential component of soil because of their involvement in nutrient cycling, and direct action on the soil pedogenesis, improving clay and silt that had percolated. It also influenced the availability and translocation of some primary and secondary macronutrients and increases the porosity, aeration, water infiltration.

Key words: grassland, termitary, soil.

\section{Recebido para publicação em 12/01/2010. Aprovado em 16/02/2012.}

1- Mestrando UFT (Relação Solo x Planta x Animal). Bolsista CAPES, tavernyzoot@yahoo.com.br

2- Professor Adjunto da Universidade Federal do Tocantins, Bolsista Produtividade CNPq, clementino@uft.edu.br

3- Doutorando UFT (Relação Solo x Planta x Animal) - Bolsista CAPES, sabinozootec@yahoo.com.br

4- Professor Adjunto da Universidade Federal do Tocantins, Bolsista Produtividade CNPq, jecs@uft.edu.br, paivaeu@yahoo.com

\section{REVENG}




\section{INTRODUÇÃO}

A pecuária brasileira é conduzida, quase na sua totalidade, no sistema produtivo de extrativismo da pastagem e, principalmente, dos recursos de produção do solo que induzem a inércia natural e gradual da aceleração da degradação edáfica e quebra da sustentabilidade do mesmo, levando ao aparecimento de comunidades invasoras nas pastagens. Dentre os mais comuns estão os cupins de montículo, que constroem seus termiteiros.

A invasão dos térmitas nas pastagens está coincidente com o solo em estágio avançado de degradação, o que leva alguns técnicos a agregar este último fator como indicativo de deterioramento do vigor produtivo da pastagem. Segundo Zanine et al. (2005), estipula-se que cerca de 50 milhões de hectares no cerrado estejam em algum estágio de degradação, com perda da capacidade natural de regeneração, tendo como fator principal a exploração irracional dos recursos de produção do solo e perda da biota do solo que são de extrema importância na dinâmica biogênica do solo (COSTA et al., 2007).

As pastagens tropicais possuem uma deposição de matéria orgânica de melhor qualidade, com menor percentual de parede lignificada que a liteira das áreas de florestas nativas, bem como a maior concentração de raízes de gramíneas nas proximidades da camada arável do solo (MOREIRA ; SIQUEIRA, 2006). A matéria orgânica de melhor qualidade a ser humificada favorece para que os térmitas invadam as pastagens em busca de alimento. Muito embora se ouça falar sobre perdas econômicas atribuídas aos termiteiros, esta situação está mais vinculada a mitos populares do que a notória situação discorrida nas fazendas brasileiras.

É fato que os termiteiros são abrigo para animais peçonhentos, porém, estes animais se abrigam nestes locais durante o dia para repousarem, horário de maior trânsito animal pela área, e saem durante a noite, portanto, dificilmente um bovino será acometido por um indivíduo venenoso em um termiteiro. Dessa forma, os cupinzeiros não trazem prejuízos reais, mas inconvenientes de manejo da área, como em atividades de mecanização, dificultando a locomoção do trator e enterramento de canos.

Os cupins são comumente rotulados de pragas nas pastagens, embora o grupo dos cupins-pragas, consumidoras de folhas verdes de gramíneas, compõe uma minoria não chegando a $10 \%$ (Syntermes, Heterotermes e etc.), dos quais não se enquadram os térmitas construtores de montes epígeos, pois são consumidores de restos de gramíneas mortas. Esses insetos são importantíssimos agentes biológicos dos fatores biogênicos do solo, atuando de forma efetiva e acelerando a decomposição e mineralização de materiais lignificados e celulósicos (TAYASU et al., 1997; COSTA-LEONARDO, 2002). Os térmitas são organismos importantes para a manutenção da dinâmica dos processos bioquímicos de carbono e nutrientes nos ambientes florestais em regiões tropicais, devido principalmente à biomassa de suas populações e à variedade de seus hábitos alimentares (MATSUMOTO, 1976; BIGNELL; EGGLETON, 2000; BANDEIRA; VASCONCELLOS, 2002).

Os térmitas promovem revolvimento seletivo do solo transportando partículas cimentantes (silte e principalmente argila) para construção dos montes epígeos, e junto aos colóides de argila são carreados, também, elementos que foram percolados nos perfis do solo, promovendo assim o transporte e reciclagem de nutrientes. A atividade das térmitas na pastagem aumenta o volume do solo de melhor qualidade na superfície de área cultivável. A seleção dos térmitas por argilominerais aumenta a porosidade do solo em profundidade e, como consequência, aumenta a aeração e infiltração de água até as raízes das forrageiras. Eldridge (1994), em trabalhos com térmitas no semiárido australiano, enfoca o papel das estruturas de canais subterrâneos provenientes de termiteiros na capacidade de infiltração de água dos solos.

A construção dos termiteiros (ninhos) pelos térmitas provoca modificações também no subsolo, como a construção de galerias subterrâneas, o que leva ao aumento de porosidade e aeração do solo (LEE; WOOD, 1971; WOOD; SANDS, 1978). Para Amelung et al. (2001), solos com maiores taxas de matéria orgânica compõem em seu ambiente alta concentrações de invertebrados (colêmbolos, térmitas e etc.) em sua biota na busca por condições 
edafoclimáticas adequadas ao desenvolvimento das colônias com boa oferta de alimento, fato atrelado a peculiaridade das pastagens que favorecem a colonização pelos cupins.

A evolução do desenvolvimento biológico dos cupins proporcionou alterações adaptativas primordiais a sua sobrevivência, de forma a se instalarem em diversos ambientes de acordo com o que lhes oferece, tais como tamanho da colônia, a história de vida, o desenvolvimento de castas e os habitats (ninhos), estão associados à disponibilidade de recursos alimentares (ABE, 1987; LENZ, 1994).

Os térmitas, ou cupins como são conhecidos no Brasil, são insetos pertencentes à ordem Isoptera, e apresentam quase três mil espécies descritas, que estão distribuídas em sete famílias, no entanto, as mais importantes existentes no Brasil: Rhinotermitidae, Serritermitidae e Termitidae (SHELLMAN-REEVE, 1997), sendo esta última família onde se englobam alguns gêneros de térmitas que constroem montes conspícuos de argila.

Os cupins possuem alimentações semelhantes a dos ruminantes extraindo eficientemente os nutrientes de vegetais através da fermentação de compostos da parede celular. A diferença entre ambos são alguns dos compostos utilizados e o estágio do vegetal, pois os cupins utilizam tanto compostos fenólicos (lignina) como celulósicos. Embora estes últimos desdenhem preledição, os quais devem estar às folhas senescentes e em contato direto com o solo. $\mathrm{O}$ intestino é formado por cinco compartimentos apresentando oscilações de $\mathrm{pH}$, em até 12,5 e status diferente do oxigênio e do hidrogênio (BRUNE et al., 1995; DONOVAN et al., 2001; EGGLETON; TAYASU, 2001).

O Brasil, de acordo com Constatino (2005), é o único país da América Latina com tradição no estudo dos cupins, e sua fauna é a mais bem conhecida da região, com cerca de 280 espécies registradas. No entanto, as pesquisas estão limitadas ao sítio da entomologia, sendo extremamente precárias informações sobre seu comportamento, funções no ambiente solo e das alterações físico-químicas. Além disso, as informações sobre esse assunto são sobre espécies das regiões centro e sudeste do Brasil as quais são distintas da espécie que infestam as pastagens tocantinenses, sendo assim de hábitos apenas semelhantes.

O presente trabalho teve como objetivo avaliar a composição dos termiteiros sobre pastagem comparando às alterações das propriedades químicas e físicas do solo adjacente causadas pelos térmitas.

\section{MATERIAL E MÉTODOS}

As propriedades escolhidas tiveram que atender a alguns requisitos pré-estabelecidos tais como possuir no mínimo 10 ha de pastagem, sob o mesmo tipo de solo dos quais cumpririam ser Neossolo ou Latossolo, classificados, segundo EMBRAPA (2006), não ter realizado controle de cupins por métodos físicos, químicos ou biológicos nos últimos seis anos de cultivo da pastagem, a qual deveria ser de Brachiária brizantha $\mathrm{cv}$. Marandu em todas as áreas estudadas e os ninhos em estudo deveriam ter altura mínima de 1 $\mathrm{m}$, as quais receberam as denominações descritas no Quadro 1.

As amostras foram colhidas de quatro áreas diferentes sob dois tipos de solos distintos, sendo duas propriedades em Latossolo Vermelho Distrófico típico e outras duas em Neossolo Quartzarênico Órtico típico.

As coletas dos termiteiros constaram de apenas quatro áreas onde havia infestações (T1, T2, T3, T4), onde foram coletadas amostras do solo na camada de 0-30 cm de profundidade. Essas amostras serviram para comparação experimental entre áreas infestadas sob a pastagem. As mesmas áreas foram fotografadas para visualização ocular e auxiliar a diagnose da emergência termítica.

Foram amostrados cinco termiteiros por área de pastagem em Brachiária brizantha, cv. Marandu e coletado solo da pastagem adjacente em cinco pontos.

Quadro 1. Identificação e caracterização das áreas estudadas

\begin{tabular}{cccc}
\hline Área & Terminologia & Tipo de solo & ${\text { Infestação } \mathrm{n}^{\mathrm{o}} \text { cupins ha }}^{-1}$ \\
\hline Estância & T1 & LATOSSOLO VERMELHO & 20 \\
& T2 & LATOSSOLO VERMELHO & 10 \\
Assentamento Alegre & T3 & NEOSSOLO QUARTZARÊNICO & 80 \\
& T4 & NEOSSOLO QUARTZARÊNICO & 14 \\
\hline
\end{tabular}

\section{REVENG}


Os montículos foram fragmentados com picareta, tendo minucioso cuidado durante a coleta para evitar contaminação de fragmentos de outras partes do termiteiro com o solo da pastagem, coletando amostras do topo, centro, base e solo adjacente ao termiteiro, com raio de $1,5 \mathrm{~m}$ de distância da periferia circunférica, a fim de estudar a área que sofre interferência direta da ação dos térmitas. O centro corresponde à porção mais interna do termiteiro. Todas as amostras foram devidamente acondicionadas em sacos plásticos e transferidas ao laboratório de solos da Universidade Federal do Tocantins, onde se procederam as análises químicas e físicas.
A Figura 1 ilustra as zonas de divisão imaginária do termiteiro e solo adjacente das pastagens descritas anteriormente, utilizadas para o fracionamento e coleta. As amostras de solo transferidas ao laboratório foram submetidas à peneira de $2 \mathrm{~mm}$ e em seguida destorroadas $50 \mathrm{~g}$ em gral de porcelana, e colocadas em copos plásticos para espera.

O fracionamento do termiteiro é mais bem ilustrado na Figura 2, expondo a parte interna do termiteiro designada neste trabalho de centro, topo ou parte externa que compõe a camada mais rígida do monte e base, ou pé que corresponde à área de transição entre o solo adjacente (solo da pastagem) e o termiteiro.

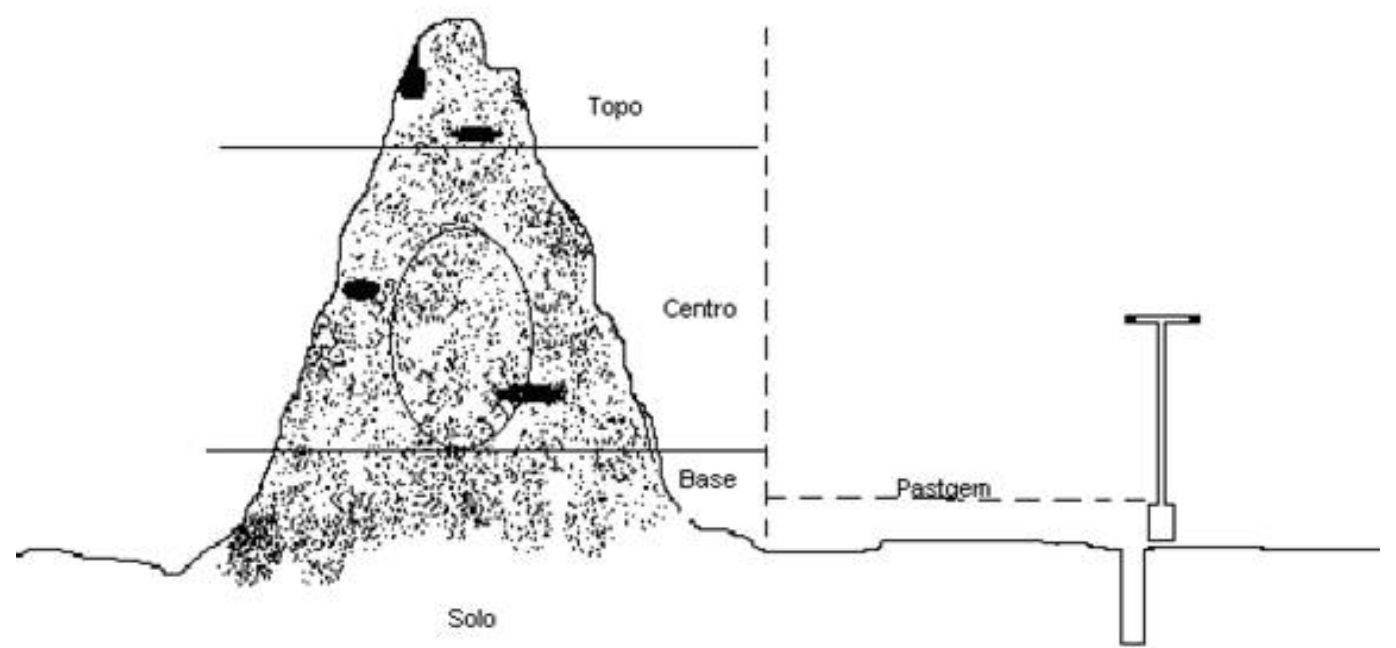

Figura 1. Ilustração das divisões de seccionamento para coleta de campo dos termiteiros.

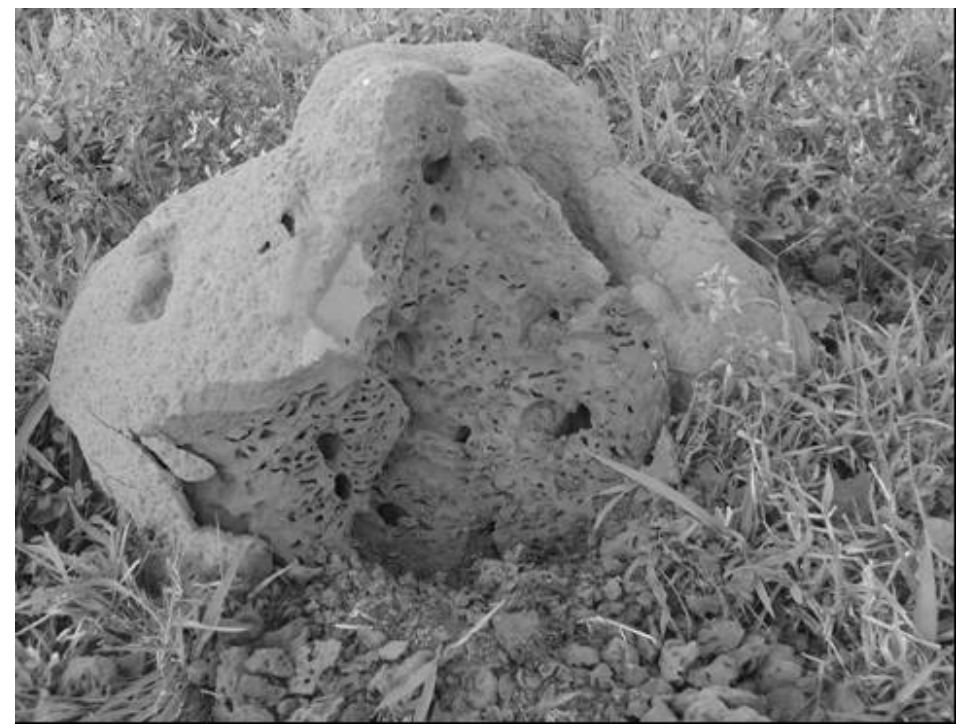

Figura 2. Termiteiro epígeo de térmitas endêmicas (Procornitermes sp.) das pastagens da microrregião de Araguaína. Termiteiro fracionado. 
Os mesmos termiteiros fracionados para coleta das amostras do topo, centro e base, foram destruídos até o interior do ninho como mostra na figura 2, a fim de se coletar no mínimo 10 operários e 10 soldados para efetuar-se a classificação taxonômica da espécie de cada área. A coleta e identificação dos insetos seguiram a chave de identificação das espécies (CONSTATINO, 1999). Os cupins foram coletados com pincel macio de construção civil, acondicionados em recipientes de plásticos e conduzidos ao laboratório de zoologia da Universidade Federal do Tocantins em um prazo máximo de 5 horas onde foram colocados em álcool a $80 \%$ para conservação dos insetos. Os cupins das quatro áreas foram identificados como do gênero Procornitermes spp.

$\mathrm{O}$ experimento foi organizado em arranjo fatorial 4 x 4 resultando de quatro áreas e quatro posições, sendo três porções nos termiteiros e solo adjacente dos termiteiros e cinco repetições.

As análises químicas foram procedidas segundo o manual de análises química de solos, plantas e fertilizantes da EMBRAPA (SILVA, 1999): $\mathrm{pH}$ $\left(\mathrm{CaCl}_{2}\right)$; matéria orgânica (M.O.) procedeu-se oxidação via úmida com solução de Dicromato de potássio e titulação com sulfato ferroso; fósforo disponível (P), extraído em solução Mehlich 1; potássiotrocável $\left(\mathrm{K}^{+}\right)$, cálcio trocável $\left(\mathrm{Ca}^{2+}\right)$, magnésio trocável $\left(\mathrm{Mg}^{2+}\right)$ e alumínio trocável $\left(\mathrm{Al}^{3+}\right)$ em extração com $\mathrm{KCl} 1 \mathrm{~mol} \mathrm{~L}^{-1}$. Análises físicas segundo o manual da EMBRAPA de análises químicas e físicas do solo
(EMBRAPA, 1997): argila, areia, silte pelo método de dispersão em solução com hidróxido de sódio.

Após obtenção dos dados, os mesmos foram submetidos à análise de variância, seguido pelo teste de Tukey ao nível de 5\% de probabilidade, utilizando o software Assistat versão 7.5 beta (SILVA ; AZEVEDO, 2008).

\section{RESULTADOS E DISCUSSÃO}

Resultados distintos de $\mathrm{pH}$ para cada divisão do cupim e da área adjacente. $\mathrm{O}$ topo em todas as áreas tendenciou ser sempre superior às outras porções do termiteiro, principalmente da base e solo adjacente (Figura 3). Isso é explicado durante a construção do monte, o qual é dividido em três partes: o topo ou parte externa, centro e base. A parte mais externa com espessura em torno de $10 \mathrm{~cm}$ fica em exposição direta às intempéries, o que determina aos cupins à construção de uma estrutura mais resistente a desintegração de partículas. Para tanto, é necessário a adição de grandes quantidades de saliva (VANDECASTEELE et al., 2004; LÓPEZHERNÁNDEZ et al., 2006) com elevada quantidade de carbonatos o qual mantêm $\mathrm{pH}$ do estômago dos cupins próximo ou até acima da neutralidade, podendo chegar a picos de 12 como afirmam Brune e Kühl, (1996); Brauman (2000); Ohkuma (2003) e Kaschuk et al. (2006). Assim o pH do topo chega a aproximar de 6,0 .

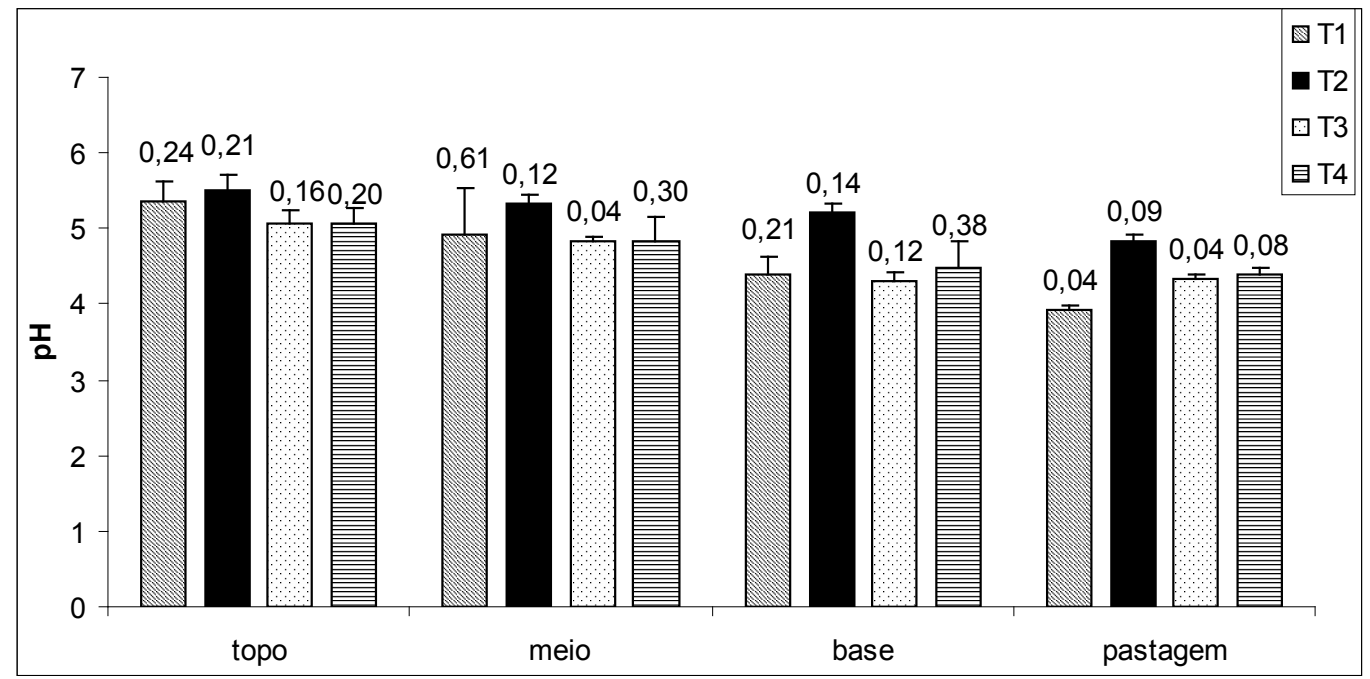

Figura 3. Análise descritiva do $\mathrm{pH}$ em $\mathrm{CaCl}_{2}$ do topo, meio e base dos termiteiros e solo da pastagem das áreas T1 (Área 1 - Latossolo), T2 (Área 2 - Latossolo), T3 (Área 3 - Neossolo), T4 (Área 4 Neossolo). Desvios Padrão sobre as barras.

122 REVENG

$118-130 \mathrm{p}$.

ENGENHARIA NA AGRICULTURA, VIÇOSA - MG, V.20 N.2, MARÇO / ABRIL 2012 
Como a parte mais externa (topo) do cupinzeiro deve ser obrigatoriamente mais resistente, nas porções internas não há necessidade de estruturas rígidas, portanto a demanda por saliva nestas partes é menor e como consequência, $\mathrm{pH}$ é mais baixo no centro (interna) do cupinzeiro que na porção externa.

$\mathrm{O}$ decréscimo gradativo no valor do $\mathrm{pH}$ do topo em comparação a pastagem, é nítida em todas as áreas, obtendo os menores níveis no solo adjacente e base do cupinzeiro. Isso porque a base possui baixa interferência construtiva dos cupins, bem como no solo da pastagem.

No Quadro 2 estão expressos os valores de matéria orgânica, argila areia e silte, das áreas de Latossolo Vermelho Distrófico (T1 e T2) e em Neossolo Quartzarênico Órtico (T3 e T4), das diferentes posições nos termiteiros e solo adjacente.

Kaschuk et al. (2006) relataram níveis de matéria orgânica mais elevada no centro dos montes do que no solo adjacente, chegando a níveis de $260 \mathrm{~g} \mathrm{~kg}^{-1}$, enquanto o presente trabalho apresenta maior concentração de matéria orgânica no centro de $55 \mathrm{~g} \mathrm{~kg}^{-1}$. Já nas porções do topo e base do termiteiro, não apresentaram nenhuma diferença em relação ao solo adjacente. No entanto, o que provavelmente propiciou para antagonismo acentuado entre as duas situações, foi à espécie endêmica da região, onde o autor citado trabalhou com Cornitermes cumulans, o qual constrói uma cápsula celulósica no centro do ninho inteiramente de material orgânico (liteira), diferentemente da espécie (Procornitermes) estudada no presente trabalho, que não confecciona a mesma estrutura.

Lee e Wood (1971), analisando características químicas de solos sob influência de 17 espécies de térmitas na Austrália, também encontraram valores de matéria orgânica maiores nos termiteiros que nos solos adjacentes para Nasutitermes triodiae, assim como o trabalho de Bandeira e Torres (1985), em termiteiros na Amazônia. Os níveis de matéria orgânica no termiteiro estão intimamente ligados ao tipo de espécie que dinamiza a distribuição e uso da mesma.

Quadro 2. Análise dos fatores físicos e matéria orgânica (M.O.) no solo e posições dos termiteiros, das áreas infestadas. Componentes físicos do solo: argila, areia e silte respectivamente $\mathrm{em} \mathrm{g} \mathrm{kg}^{-1}$

\begin{tabular}{|c|c|c|c|c|c|}
\hline \multicolumn{2}{|r|}{ Áreas } & M.O. & Argila & Areia & Silte \\
\hline & & \multicolumn{4}{|c|}{ 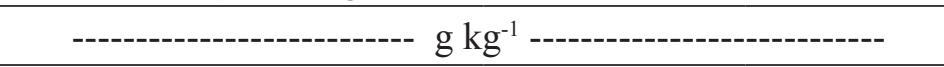 } \\
\hline \multirow{4}{*}{$\mathrm{T} 1$} & Topo & $55 \mathrm{aA}$ & 80,6 aA & $420 \mathrm{aB}$ & $493 \mathrm{aAB}$ \\
\hline & Centro & $50 \mathrm{aAB}$ & $76,6 \mathrm{aA}$ & $383 \mathrm{aB}$ & $530 \mathrm{aA}$ \\
\hline & Base & $50 \mathrm{aAB}$ & $70 \mathrm{aAB}$ & $420 \mathrm{aAB}$ & $496 \mathrm{aAB}$ \\
\hline & Solo adjacente & $47 \mathrm{aAB}$ & $60 \mathrm{aB}$ & $546 \mathrm{aA}$ & $393 \mathrm{aB}$ \\
\hline \multirow{4}{*}{$\mathrm{T} 2$} & Topo & $44 \mathrm{aAB}$ & $70 \mathrm{aA}$ & $550 \mathrm{aAB}$ & $366 \mathrm{aAB}$ \\
\hline & Centro & $54 \mathrm{aA}$ & $70,4 \mathrm{aA}$ & $520 \mathrm{aB}$ & $433 \mathrm{aA}$ \\
\hline & Base & $47 \mathrm{aAB}$ & $67,7 \mathrm{aA}$ & $540 \mathrm{aAB}$ & $390 \mathrm{aAB}$ \\
\hline & Solo adjacente & $47 \mathrm{aAB}$ & $57,2 \mathrm{aAB}$ & $580 \mathrm{aA}$ & $350 \mathrm{aB}$ \\
\hline \multirow{4}{*}{$\mathrm{T} 3$} & Topo & $49 \mathrm{aAB}$ & $20,6 \mathrm{bA}$ & $730 \mathrm{aAB}$ & $236 \mathrm{aA}$ \\
\hline & Centro & $46 \mathrm{aAB}$ & $20,4 \mathrm{bA}$ & $690 \mathrm{aB}$ & $276 \mathrm{aA}$ \\
\hline & Base & $46 \mathrm{aAB}$ & $23,9 \mathrm{bA}$ & 750 aAB & $213 \mathrm{aA}$ \\
\hline & Solo adjacente & $33 \mathrm{aB}$ & $30,4 \mathrm{bA}$ & $820 \mathrm{aA}$ & $143 \mathrm{aB}$ \\
\hline \multirow{4}{*}{$\mathrm{T} 4$} & Topo & $42 \mathrm{aAB}$ & $26,9 \mathrm{bA}$ & $740 \mathrm{aAB}$ & $226 \mathrm{aA}$ \\
\hline & Centro & $44 \mathrm{aAB}$ & $20,1 \mathrm{bA}$ & $670 \mathrm{aB}$ & $306 \mathrm{aA}$ \\
\hline & Base & $42 \mathrm{aAB}$ & $20,2 \mathrm{bA}$ & $750 \mathrm{aAB}$ & $223 \mathrm{aA}$ \\
\hline & Solo adjacente & $33 \mathrm{aB}$ & $33,8 \mathrm{bA}$ & 830 aA & $136 \mathrm{aB}$ \\
\hline CV \% & & 13 & 14 & 6 & 12 \\
\hline
\end{tabular}

Letras minúsculas compara posições dos termiteiros e solo adjacente entre as áreas (T1 Área 1 - Latossolo; T2 Área 2 - Latossolo; T3 Área 3 - Neossolo; T4 Área 4 - Neossolo) distintas (interação), e letras maiúsculas dentro das áreas, comparando topo, centro, base e pastagem dentro de uma mesma área. As variáveis foram signficativas em nível de $5 \%$ de probabilidade. 
A argila é o componente mais usado pelos térmitas para construção de seus ninhos (ALBUQUERQUE et al., 2008), em virtude de sua alta capacidade ligante que permite a estrutura que irá compor plasticidade quando seca (FLORES et al., 2007). No Quadro 2 estão apresentados os valores de argila entre áreas com distinção estatística. Nas áreas composta de Neossolo, os teores de argila no topo, centro, base e pastagem foi menor quando comparadas às áreas de Latossolo, mostrando interação. Em contrapartida não houve interação da variável entre os valores dentro das áreas quando comparados topos entre centros, bases e pastagens. Isso se deve a eficiente modelagem do termiteiro por parte dos cupins que deve conferir resistência aos ninhos. Esse fenômeno é atribuído ao potencial seletivo dos térmitas (LEE; WOOD, 1971) para construir os montes epígeos que necessitam de uma estrutura que suporte firmemente as intempéries, sendo a argila o principal componente cimentante do solo.

A argila atua como fator de unificação entre partículas fazendo um papel de cola, unindo as partículas do solo que também têm grande importância para a manutenção da umidade em suas estruturas (LEE; WOOD, 1971). Jouquet et al., (2002), em trabalho com solos tropicais, já testemunharam modificações na textura do solo ou nos minerais da argila pela ação de térmita. A mesma argila que permite melhor conformação física ao termiteiro dinamiza, também, a atividade química do solo nos colóides carregados pelos térmitas.

Os níveis de silte no solo adjacente da camada 0-30 $\mathrm{cm}$ de profundidade foram sempre mais baixos que nos montes sobre Neossolo. No âmbito da característica destes insetos de construção, seu caráter de seletividade biológica os submete a busca por outros componentes minerais de característica física semelhante à argila que possa substituí-la, mesmo que com menor eficiência de seguridade arquitetônica, esse paradigma pedogênico, não apresenta relação de silte entre as áreas. No entanto, observa-se que em todas as quatro áreas o teor de silte no centro dos cupinzeiros foi ligeiramente maior que nas outras partes do termiteiro.

As espécies que constroem seus ninhos inteiramente dentro do perfil do solo também alteram a proporção entre argila e materiais grosseiros, a partir da remoção de areia tanto fina quanto grosseira. Kaschuk et al. (2006), trabalhando com termiteiros sob Cambiossolo em Santa Catarina, encontraram valores de silte confrontantes com os níveis do Neossolos e semelhantes aos do Latossolos no Tocantins. Mas um índice contraditório foi observado por Kaschuk et al. (2006) no centro do monte, onde o índice de areia era mais elevado que a no topo e base do termiteiro.

Segundo Albuquerque et al. (2008), em trabalho com solo-cimento a partir de cupinzeiros de pastagem, o percentual das frações granulométricas de argila e silte aumentaram pronunciadamente nos montículos, com queda dos valores de areia em relação ao solo adjacente em Neossolo, entrando em concordância com o presente trabalho, onde apenas em Neossolo (Quadro 2) houve diferença nos teores de argila entre termiteiro e solo adjacente da mesma área, e pronunciado aumento de silte nos mesmos compartimentos.

Os valores de areia expressos na Tabela 2 indicam que a areia no solo adjacente foi amplamente maior quando comparada as partes de topo, centro e base do termiteiro em todas as quatro áreas, embora não apresentassem interação entre tipos de solos com as porções divididas dos termiteiros. Essa característica de seletividade dos térmitas, por partículas menores (argila e silte), aumenta os espaços vazios do solo (macroporos) deixando remanescentes na área adjacente em maior quantidade de areia, favorecendo efeitos físicos do solo, como drenagem pelas camadas subsuperficiais e aeração do subsolo, permitindo melhor aeração e percolação de água por entre os perfis.

Uma característica bastante intrigante nos termiteiros refere-se ao centro dos mesmos, os quais ofertam menores valores de areia e maiores teores de silte no interior dos ninhos tanto nas áreas de Neossolo como em Latossolo. Possivelmente estes insetos possuem uma característica genética que os induzem a tal ação comportamental, a fim de aumentar o volume e resistência externa no termiteiro misturando os componentes areia e argila. Isso leva a crer que a atividade dos cupins no solo favorece a gênese do mesmo e ciclagem de nutrientes percolados no perfil do solo, para a superfície cultivável.

\section{REVENG}

118-130 p. 
O fósforo disponível expresso no Quadro 3 demonstrou interação nos quesitos avaliados entre cupinzeiros e solo adjacente em Neossolo. No entanto, no que se refere avaliação entre áreas com Latossolo, não houve interação, sendo equivalente quando comparada aos termiteiros e ao solo adjacente. Essa característica é naturalmente aceitável, pois durante o consumo da matéria orgânica oriunda da serrapilheira ou do húmus do solo, os fosfatos orgânicos são transformados no intestino dos cupins por bactérias, submetido ao $\mathrm{pH}$ extremamente alcalino provocando a utilização efetiva de grande parte do fósforo orgânico, do qual o remanescente está na forma mineralizada (TIMOFEEV, 1987) nas excretas que são depositadas nas paredes internas do ninho em forma disponível para as plantas.

A quantidade de fósforo disponível em Neossolo
(ALBUQUERQUE et al., 2008; SEMHI et al., 2008) foi maior nos termiteiros (topo, centro e base) que no solo da pastagem, levando em consideração que o termiteiro é constituído por um percentual de argila um pouco maior, aumentando o poder de retenção, fixação e dinamismo do fósforo quanto à solubilização, imobilização e mineralização, sendo o mesmo princípio nas áreas de Latossolo para as posições dos termiteiros (topo, centro e base) e pastagem. Assim, o fósforo disponível em solos com maior teor de argila fica preso aos colóides com maior intensidade diminuindo a perda do nutriente por lixiviação.

Para a variável potássio, encontrou-se interação tanto entre áreas Latossolo (T1 e T2) e Neossolo (T3 e T4) como entre topo, centro, base e pastagem. O nível de potássio no centro dos termiteiros é maior em todos os cupinzeiros das quatro áreas

Quadro 3. Análise dos fatores químicos, das áreas infestadas, fósforo disponível melich (P), potássio trocável $\left(\mathrm{K}^{+}\right)$, cálcio trocável $\left(\mathrm{Ca}^{2+}\right)$, magnésio trocável $\left(\mathrm{Mg}^{2+}\right)$, alumínio trocável $\left(\mathrm{Al}^{3+}\right)$

\begin{tabular}{|c|c|c|c|c|c|c|}
\hline & Áreas & $\mathrm{P}$ & $\mathrm{K}^{+}$ & $\mathrm{Ca}^{2+}$ & $\mathrm{Mg}^{2+}$ & $\mathrm{Al}^{3+}$ \\
\hline & \multicolumn{3}{|c|}{$-\mathrm{mg} \mathrm{dm}^{-3}$} & \multicolumn{3}{|c|}{$\mathrm{cm}_{\mathrm{c}} \mathrm{dm}^{-3}$} \\
\hline \multirow{4}{*}{$\mathrm{T} 1$} & Topo & $1,24 \mathrm{aAB}$ & $20,06 \mathrm{aA}$ & $4,24 \mathrm{aA}$ & $3,65 \mathrm{aA}$ & $0,31 \mathrm{aA}$ \\
\hline & Centro & $1,35 \mathrm{aAB}$ & $10,39 \mathrm{abAB}$ & 2,99abA & $2,76 \mathrm{aAB}$ & $0,34 \mathrm{aA}$ \\
\hline & Base & $1,39 \mathrm{aAB}$ & $17,46 \mathrm{aA}$ & $4,60 \mathrm{aA}$ & $1,49 \mathrm{abC}$ & $0,39 \mathrm{aA}$ \\
\hline & Solo adjacente & $1,17 \mathrm{aAB}$ & $8,58 \mathrm{abB}$ & $1,14 \mathrm{abB}$ & $2,48 \mathrm{aBC}$ & $0,45 \mathrm{aA}$ \\
\hline \multirow{4}{*}{$\mathrm{T} 2$} & Topo & $1,58 \mathrm{aAB}$ & $14,81 \mathrm{aAB}$ & $4,57 \mathrm{aA}$ & $1,24 \mathrm{bA}$ & $0,35 \mathrm{aA}$ \\
\hline & Centro & $1,56 \mathrm{aAB}$ & $19,06 \mathrm{aA}$ & $4,47 \mathrm{aAB}$ & $1,88 \mathrm{aA}$ & $0,39 \mathrm{aA}$ \\
\hline & Base & $1,37 \mathrm{aAB}$ & $11,11 \mathrm{abB}$ & $3,97 \mathrm{abAB}$ & $1,52 \mathrm{abA}$ & $0,32 \mathrm{aA}$ \\
\hline & Solo adjacente & $1,10 \mathrm{aAB}$ & $8,91 \mathrm{abB}$ & $2,83 \mathrm{aB}$ & $1,79 \mathrm{abA}$ & $0,49 \mathrm{aA}$ \\
\hline \multirow{4}{*}{$\mathrm{T} 3$} & Topo & $1,66 \mathrm{aA}$ & $7,43 \mathrm{bBC}$ & $1,09 \mathrm{bA}$ & $1,62 \mathrm{abA}$ & $0,22 \mathrm{aA}$ \\
\hline & Centro & $1,18 \mathrm{aA}$ & $16,93 \mathrm{aA}$ & $1,21 \mathrm{cA}$ & $1,60 \mathrm{abA}$ & $0,29 \mathrm{aA}$ \\
\hline & Base & $1,65 \mathrm{aA}$ & $9,91 \mathrm{bB}$ & $2,48 \mathrm{bcA}$ & $1,14 \mathrm{abA}$ & 0,18 aA \\
\hline & Solo adjacente & $0,90 \mathrm{aB}$ & $3,39 \mathrm{bC}$ & $0,93 \mathrm{bAB}$ & $0,87 \mathrm{bcA}$ & $0,30 \mathrm{aA}$ \\
\hline \multirow{5}{*}{$\mathrm{T} 4$} & Topo & $1,66 \mathrm{aA}$ & $16,88 \mathrm{aA}$ & $1,82 \mathrm{bAB}$ & $1,08 \mathrm{bA}$ & $0,39 \mathrm{aA}$ \\
\hline & Centro & $1,62 \mathrm{aA}$ & $15,66 \mathrm{abA}$ & $2,37 \mathrm{bcA}$ & $1,13 \mathrm{bA}$ & $0,33 \mathrm{aA}$ \\
\hline & Base & $1,68 \mathrm{aA}$ & $15,60 \mathrm{abA}$ & $2,0 \mathrm{cA}$ & $0,72 \mathrm{bcA}$ & $0,33 \mathrm{aA}$ \\
\hline & Solo adjacente & $0,73 \mathrm{aB}$ & $12,07 \mathrm{aA}$ & $0,54 \mathrm{bB}$ & $0,21 \mathrm{cA}$ & $0,40 \mathrm{aA}$ \\
\hline & $\mathrm{CV} \%$ & 20 & 22 & 29 & 29 & 26 \\
\hline
\end{tabular}

Letras minúsculas compara posições dos termiteiros e solo adjacente entre as áreas (T1 Área 1 - Latossolo; T2 Área 2 - Latossolo; T3 Área 3 - Neossolo; T4 Área 4 - Neossolo) distintas (interação), e letras maiúsculas dentro das áreas, comparando topo, centro, base e pastagem dentro de uma mesma área. As variáveis foram significativas em nível de $5 \%$ de probabilidade. 
quando comparados ao topo base e pastagem. Isso acontece devido à exposição direta do topo às intempéries e o fraco poder de adsorção das argilas das regiões tropicais.

As chuvas conseguem carregar com maior facilidade o potássio trocável; aderido aos colóides que compõe a estrutura epígea, levando o elemento de volta ao solo, ao contrário da base que entra em contato íntimo com a superfície do solo, que apresentou valores baixos quando comparados ao topo, centro e base (BANDEIRA ; VASCONCELOS, 2002). No entanto, o centro do ninho fica protegido das variações climáticas, além de ter o potássio nas paredes dos termiteiros de fonte orgânica. Assim, as diferentes formas de potássio, principalmente o potássio trocável aderido às argilas, fica distante da ação da chuva.

O teor de potássio trocável no solo adjacente é consideravelmente menor que as divisões dos termiteiros tanto nas áreas de Neossolo quanto em Latossolo, mas os níveis do elemento no topo, centro e base não apresentaram consistente diferença entre as áreas de solos. Este fato provavelmente deve-se ao poder seletivo dos cupins, os quais coletam preferencialmente argila para construção do monte. Dessa forma, naturalmente, colóides minerais contêm mais íons potássio ligados. Segundo Breznak e Brune (1994), Brune et al. (1995) e Brune e Kuhl (1996), o elevado pH do estômago dos cupins também pode esclarecer o elevado teor de potássio trocável nos termiteiros, já que alcalinidade altera a configuração de alguns compostos minerais (LU et al., 2003; RIVES et al., 2004), que em solos argilosos possuem consideráveis quantidades de potássio adsorvidos nas argilas ou como minerais secundários.

O cálcio trocável presente nos termiteiros é terminantemente maior $(\mathrm{P}<0,05)$ que no solo adjacente em todas as áreas (BANDEIRA; TORRES, 1985). Enfatiza-se que nas áreas de Neossolos apresentaram-se valores de cálcio inferiores às áreas de Latossolo, tanto em termiteiro quanto em pastagem. O Neossolo contém baixo poder de adsorção para cálcio trocável devido a deficiente retenção do complexo coloidal, o que aumenta substancialmente a lixiviação dos íons de cálcio propiciando aumento da acidez do solo, já que este elemento possui menor poder de retenção que os íons de hidrogênio. No entanto, o que se observa é o aumento absoluto do mesmo íon nos termiteiros nas duas áreas (Latossolo e Neossolo). Dessa forma, levanta-se duas questões. Durante a seleção por partículas os cupins buscam principalmente argila, chegando até abaixo da camada arável do solo. O cálcio percolado pelos perfis do solo ligado a esses colóides são levados por estes insetos para comporem os termiteiros ou, o procuram devido sua alta capacidade ligante entre argilominerais que favorecem a performance física e durabilidade do termiteiro.

Ao contrário do que afirma Kaschuk et al. (2006), as concentrações de cálcio não foram maiores no centro dos termiteiros em nenhuma das áreas. Isso decorre devido característica comportamental das espécies estudadas. A espécie estudada pelos autores citados é endêmica daquela região e o seu hábito instintivo é de construir ninhos cartonados com material orgânico no interior dos termiteiros, elevando abruptamente as concentrações de fósforo, magnésio e potássio no interior dos ninhos.

Além do carregamento do cálcio percolado, os cupins também transportam para dentro do ninho matéria orgânica oriunda de serrapilheira, os quais constituem algumas partes de tecidos de plantas e são liberados no interior dos termiteiros pelas fezes dos operários.

A busca dos cupins pelo cálcio pode ser também em decorrência da manutenção do $\mathrm{pH}$ do seu estômago que deve ser mantido em níveis próximo da alcalinidade, com produções de carbonatos de cálcio, a fim de manter em constante equilíbrio a biota presente nos compartimentos de digestão. Dessa forma, durante a construção do ninho no uso de sua saliva, os cupins acabam por incorporar os íons de cálcio na argila que confeccionará o ninho.

Para o magnésio, embora somente na primeira área de Latossolo apresentasse distinção dentre si, as demais áreas de Latossolo e Neossolo não diferenciaram das divisões dos termiteiros e área adjacente. No entanto, quando referese ao topo, centro, base e área adjacente, estes mostram distinção ao serem comparados entre as áreas. Na área T2 (Latossolo) no topo, centro, base, área adjacente e T3 e T4 (Neossolo), os níveis de magnésio no topo, centro e base foram 
superiores aos valores encontrados no solo adjacente das áreas de Neossolo (BANDEIRA; TORRES, 1985) como visto no Quadro 3. Isso é explicado pela complexação de íons da camada arável, características climáticas, principalmente as chuvas e potencial seletivos dos cupins. A energia de retenção do magnésio é menor que a do hidrogênio e cálcio, respectivamente. Logo, regiões com elevada precipitação pluviométrica, como a região centro-norte, aumenta a perda deste íon da camada arável (solo adjacente) para as camadas subsuperficiais; principalmente em solos com deficiência em coloides. O magnésio segue mesmo princípio de recuperação que o cálcio, resgate dos íons das camadas mais profundas para a superfície, bem como a aceleração do processo de decomposição do material em decomposição de tecidos vegetais como a clorofila (COSTA, 2004).

$\mathrm{O}$ alumínio não foi igual em todas as áreas e em todas as divisões dos termiteiros. Talvez o alto poder de adsorção no complexo coloidal do solo dificulte a liberação deste íon para as camadas mais profundas, ligando-se com maior energia as argilas e percolado com maior dificuldade pelos perfis do solo. Assim, a área de abrangência do íon é maior, deixando pouca opção de seleção aos cupins. Ao contrário do que afirmam Sahin et al. (2008) em seu trabalho, as concentrações de alumínio nos termiteiros, no presente trabalho, não foi aumentada em relação ao solo adjacente.

\section{CONCLUSÕES}

- Os cupins melhoram os teores de argila e silte antes translocados no perfil do solo na superfície.

- As térmitas aumentam os teores de $\mathrm{P} \mathrm{Ca}^{2+}$, $\mathrm{K}^{+}, \mathrm{Mg}^{2+}$, além de contribuir na porosidade, aeração, infiltração de água de solos; e

- A quantidade de partículas cimentantes transportadas para a superfície do solo é aumentada favorecendo a retenção de água.

\section{AGRADECIMENTOS}

Os autores agradecem ao Conselho Nacional de Desenvolvimento Científico e
Tecnológico (CNPq) e a CAPES pelo apoio e bolsas concedidas

\section{REFERÊNCIAS BIBLIOGRÁFICAS}

$\mathrm{ABE}, \mathrm{T}$. Evolution of the life types in termites. In: KAWANO S., CONNEL J.H., HIDAKA T., eds. Evolution, coadaptation, and biotic communities. University of Tokyo Press, Tokyo, 1987. p.128-148.

ALBUQUERQUE, L.Q.C., BISCARO, G.A., NEGRO, S.R.L., OLIVEIRA, A.C., CARVALHO, L.A., LEAL, S.T. Resistência a compreensão de tijolos de solo-cimento fabricados com o montículo do cupim, Cornitermes cumulans (Kollar, 1832). Ciência e Agrotecnologia., Lavras, v.32, n.2, p.553560, março/abril, 2008.

AMELUNG, W.; KIMBLE, J.M.; SAMSONLIEBIG, S.; FOLLETT, R.F. Restoration of microbial residues in soils of the conservation reserve program. Soil Science of American Journal, Salt Lake Cty, v.65, n.6, p.1704-1709, novembro/ dezembro, 2001.

BANDEIRA, A.G.; TORRES, M.F. Abundância e distribuição de invertebrados do solo em ecossistemas da Amazônia Oriental. O papel ecológico dos cupins. Boletim do Museu Paraense Emílio Goeldi, Belém, v.2, n.1, p.13-38, jan, 1985. Série Zoologia

BANDEIRA, A.G.; A. VASCONCELOS. A quantitative survey of termites in a gradient of disturbed highland forest in Northeastern Brazil (Isoptera). Sociobiology, Chicago, v.39, n.3, p.429-439, march, 2002.

BIGNELL, D.E.; EGGLETON, P. Termites in ecosystems. In: ABE T., BIGNELL D.E., HIGASHI M. (eds.). Termites: Evolution, sociality, symbiosis, ecology. Dordrecht, Kluwer: Academic Publishers, 2000. p.363- 387.

BRAUMAN, A. Effect of gut transit and mound deposit on soil organic matter transformations 
in the soil feeding termite: A review. European Journal of Soil Biology, Paris, v.36, n.3-4 p.117125, julho/dezembro 2000.

BREZNAK, J.A.; BRUNE, A. Role of microorganisms in the digestion of lignocellulose by termites. Ann. Rev. Entomol, Stanford, v.39, n.1, p.453-487, Janeiro, 1994.

BRUNE, A.; EMERSON, D.; BREZNAK, J.A. The termite gut microflora as an oxygen sink: microelectrode determination of oxygen and $\mathrm{pH}$ gradients in guts of lower and higher termites. Applied and Environmental Microbiology, Michigan, v.61, n.7, p.2681-2687, julho, 1995.

BRUNE, A.; KÜHL, M. pH profiles of the extremely alkaline hindguts of soil-feeding termites (Isoptera: Termitidae) determined with microelectrodes. Journal of Insect Physiology, v.42, n.11-12, p.1121-1127, november/december, 1996.

CLAESSEN, M.E.C., BARRETO, W.O., PAULA, J.L., DUARTE, M.N. Manual de métodos de analise de solo. 2ed. Centro Nacional de Pesquisa de Solos: Rio de Janeiro, 1997. 212p. (EMBRAPACNPS. Documentos;1)

CONSTANTINO, R. Chave ilustrada para identificação dos gêneros de cupins (Insecta: Isoptera) que ocorrem no Brasil. Papéis Avulsos de Zoologia, São Paulo. v.40, n.25, p.387-448, novembro, 1999.

CONSTANTINO, R. Padrões de diversidade e endemismo de termites no bioma Cerrado. In: SCARIOT, A.; SILVA, J.C.S.; FELTILI, J.M. (Org.). Cerrado: ecologia, biodiversidade e conservação. Brasília: Ministério do Meio Ambiente. 2005, p.319-333.

COSTA, N.L.; MAGALHÃES, J. A.; PEREIRA, R.G.A.; TOWNSEND, C.R.; OLIVEIRA, J.R.C.; Considerações sobre o manejo de pastagens na Amazônia Ocidental. Revista do Conselho Federal de Medicina Veterinária, Brasília, n.40, v. 13, p.37-56, out, 2007.
COSTA, P. Fauna edáfica e sua atuacão em processos do solo. Boa Vista: Embrapa Roraima, 2004. 32p. (Embrapa Roraima. Documentos, 2).

COSTA-LEONARDO, A.M. Cupins-praga: morfologia, biologia e controle. (1.ed.). Ana Maria Costa-Leonardo, Rio Claro, SP. 2002, v.1. p.128.

DONOVAN, S.E.; EGGLETON, P.; DUBBIN, W.E.; BATCHELDER, M.; DIBOG, L. The effect of a soil feeding termite, Cubitermes fungifaber (Isoptera: Termitidae) on soil properties: termites may be an important source of soil microhabitat heterogeneity in tropical forests. Pedobiologia, Bayreuth, Germany, v.45, n.1, p.1-11, novembro, 2001.

EGGLETON, P.; TAYASU, I. Feeding groups, lifetypes and the global ecology of termites. Ecological Research, Victoria, v.16, n.5, p.941960, dec., 2001.

ELDRIDGE, D.J. Nests of ants and termites influence infiltration in a semi-arid woodland. Pedobiologia. Bayreuth, Germany, v.38, n.6, p.481-492, 1994.

EMBRAPA. Manual de métodos de análise de solo. 2 ed. ver. Atual: Centro Nacional de Pesquisa em Solos, Rio de Janeiro, RJ. 1997. 212p.

EMBRAPA. Sistema Brasileiro de Classificação de Solos. 2 ed. Centro Nacional de Pesquisa em Solos, Rio de Janeiro, 2006. 306p.

FLORES, O.J.U .; MENDES L.; PRETTE, A.L.G.; FREDEL, M.C.; AL-QURESHI, H.A.; HOTZA, D. Modelagem matemática da plasticidade de argilas com diferentes teores de umidade. In: 51 Congresso Brasileiro de Cerâmica, 2007, Salvador, BA. Anais do 51 Congresso Brasileiro de Cerâmica, 2007, v.1- 08, p.1-12.

JOUQUET, P.; MAMOU, L.; LEPAGE, M.; VELDE, B. Effect of termites on clay minerals in tropical soils: fungus-growing termites as weathering agents. European Journal of Soil 
Science, Tjele, Denmark, v.53, n.1, p.521-527, dezembro, 002.

KASCHUK, G.; SANTOS, J.C.P.; ALMEIDA, J.A.; SINHORATI D, C.; BERTON-JUNIOR J.F. Térmite activity in relation to natural grassland soil attributes. Scientia Agricola, Piracicaba, v.63, n.6, p.583-588, nov./dec., 2006.

KÖPPEN, W. Climatologia con un studio de los climas de la Tierra. México. Fondo de Cultura Econômica. 1948. 478p.

LEE, K.E.; WOOD, T.G. Physical and chemical effects on soils of some Australian termites, and their pedological significance. Pedobiologia, Levieux, v.11, n.9, p.376-409, levieux, 1971.

LEE, K.E.; WOOD, T.G. Termites and soils. London and New York, Academic Press, 1971. $251 \mathrm{p}$.

LENZ, M. Food resources, colony growth and caste development in wood-feeding termites. In. HUNT J.H., NALEPA C.A., eds. Nourishment and evolution in insect societies. Westview Press, Boulder, 1994, p.159-210.

LÓPEZ-HERNENDEZ, D., BROSSARD, M., FARDAU, J. C.; LEPAGE, M. Effect of different termite feeding groups on $\mathrm{P}$ sorption and $\mathrm{P}$ availability in African and South American savannas. Biology and Fertility of Soils, Salt Lake City, v.42, n.3, p.207-214, fevereiro, 2006.

LU, A.; GAO, X.; QIN, S.; WANG, C. Cryptomelane (KxMn8-xO16): Natural active octahedral molecular sieve (OMS-2). Chinese Science Bulletin, Beijing 100717, China, v.48, n.9, p.920-923, march, 2003.

MATSUMOTO T. The role of termites in an equatorial rain forest ecosystem of West Malaysia: Population density, biomass, carbon, nitrogen and calorific content and respiration rate. Oecologia, Germany, v.22, n.2, p.153-178, feb. 976.

MOREIRA, F.M.S.; SIQUEIRA, J.O.
Microbiologia e bioquímica do solo. $2^{\mathrm{a}} \mathrm{Ed}$. Lavras: Editora UFLA, 2006, 729p.

OHKUMA, M. Termite symbiotic systems: efficient biorecycling of lignocellulose. Applied and Environmental Microbiology, New York, v.6, n. 1, p.11-19, march, 2003.

RIVES, V.; DEL ARCO, M.; PRIETO, O. Birnessites prepared by ion exchange. Structural evolution with temperature. Boletin de la Sociedad Española de Cerámica y Vidrio, Madrid, v.43, n.2, p.142-147, 2004.

SEMHI, K.; CHAUDHURI, S.; CLAUER, N.; BOEGLIN, J.L. Impact of termite activity on soil environment: A perspective from their soluble chemical components. Internation Journal of Environmental Science and Technology, Arlington Heights, v.5, n.4, p.431-444, september, 2008.

SHELLMAN-REEVE, J.S. The espectrum of eusociality in termites, In: CHOE J.C., CRESPI B.J. (eds.). The Evolution of Social Behaviour in Insects an Arachnids. Cambridge University Press, England. 1997, p.52-93.

SILVA, F.C. Manual de análises químicas de solos, plantas e fertilizantes. EMBRAPA: Brasília, DF. 1999. 370p.

SILVA, F. A. S.; AZEVEDO, C. A. V. Versão do programa computacional Assistat para o sistema operacional Windows. Revista Brasileira de Produtos Agroindustriais, Campina Grande, v.4, n.1, p.71-78, 2002.

TAYASU, I.; ABE, T.; EGgLETON, P.; BIGNELL, D.E. Nitrogen and carbon isotope ratios in termites: an indicator of trophic habit along the gradient from wood-feeding to soilfeeding. Ecological Entomology. v.22, n.3, p.343-351, august, 1997.

TIMOFEEV, B.V. A biological factor in tropical pedogenesis. Moscow University Soil Science Bulletin, Moscou, v.42, n.1, p.70-72, 1987. 
VANDECASTEELE, B.;SAMYN, J.; QUATAERT, P.; MUYS, B.; TACK, F.M.G., Earthworm biomass as additional information for risk assessment of heavy metal biomagnification: a case study for dredged sediment-derived soils and polluted floodplain soils. 3 ed. Environmental Pollution, 129. p.363-375, 2004.

WOOD, T.G.; SANDS, W.A. The role of termites in ecosystems, p.245-292. In: BRIAN
M.V. (ed.). Production ecology of ants and termites. Cambridge, Cambridge University Press, 1978, 409p.

ZANINE, A.M.; SANTOS, E.M.; FERREIRA, D.J. Possíveis causas da degradação de pastagens. Revista Eletrônica de Veterinária REDVET, v. 4, n.11, 2005. Disponível em: http://www.veterinaria. org/revistas/redvet/n111105.html, Acesso em: Agosto de 2009. 